\title{
Dairy calcium intake and lifestyle risk factors for bone loss in hiv-infected and uninfected mediterranean subjects
}

Valentina Li Vecchi ${ }^{1}$, Maurizio Soresi ${ }^{1 *}$, Lydia Giannitrapani ${ }^{1}$, Giovanni Mazzola ${ }^{2}$, Sara La Sala ${ }^{3}$, Fabio Tramuto ${ }^{3}$, Giuseppe Caruso ${ }^{4}$, Claudia Colomba ${ }^{3}$, Pasquale Mansueto ${ }^{1}$, Simona Madonia ${ }^{3}$, Giuseppe Montalto ${ }^{1}$ and Paola Di Carlo ${ }^{3}$

\begin{abstract}
Background: Despite the reported high prevalence of osteoporosis in the human immunodeficiency virus (HIV)-population, there have been no previous studies examining dairy calcium intake and bone mineral density (BMD) in HIV-subjects.

We assessed the prevalence of low BMD in HIV-infected and uninfected subjects and analyzed the effects of calcium intake, lifestyle and HIV-related risk factors on BMD.

Methods: One hundred and twelve HIV-infected subjects were consecutively enrolled. Seventy- six HIV-uninfected subjects matched for age and sex were enrolled as the control group. The HIV-subjects were interviewed about lifestyle habits and completed a weekly food-frequency questionnaire to estimate calcium intake. HIV-RNA, CD4+ T-cell count and data on antiretroviral therapy were also recorded. Both biochemical bone turnover markers and $B M D$, assessed by dual-energy radiographic absorptiometry (DXA) were recorded in the HIV-cases and controls. We also calculated the 10-year fracture risks using the WHO FRAX equation.
\end{abstract}

Results: Osteoporosis prevalence was significantly higher in the HIV-cases than controls $(p<0.05)$. BMI values were positively correlated with BMD $(p<0.05)$. Vitamin D levels were lower in the HIV-subjects $(p<0.02)$. No correlation was found with daily calcium intake.

BMI values were significantly correlated with dairy intake quartiles $(p<0.003)$. In HIV-subjects, the mean of FRAX score was $1.2 \%$ for hip and $4.7 \%$ for major osteoporotic fractures. On multivariate analysis of the lumbar spine DXA T-score, age $(p<0.005)$ and HIV/hepatitis $C$ virus co-infection $(p<0.0001)$ were negatively correlated with $\mathrm{BMD}$, while yogurt intake was a protective predictor of BMD $(p<0.05)$. In the femur DXA T-score, age $(p<0.01)$, nadir CD4 + T-cell count $<200$ cells/ $\mu \mathrm{L}(p<0.05)$ and drug addiction $(p<0.0001)$ were negatively correlated with BMD.

Conclusions: Among the foods rich in calcium, yogurt was a protective predictor of BMD in HIV-subjects. HIV/HCV co-infection, nadir CD4 + T-cell count $<200$ cells/ $\mu \mathrm{L}$ and drug addiction were independent predictors of severe BMD. Promoting behavioral changes in food intake and lifestyle, aimed the primary prevention of bone disease in the chronically-infected subjects seems to be essential for implementing medical intervention in these cases.

Keywords: HIV, Osteopenia, Osteoporosis, Dairy intake, Bone mineral density

\footnotetext{
* Correspondence: maurizio.soresi@unipa.it

${ }^{1}$ Dipartimento di Medicina Interna, Università di Palermo, Via del Vespro 141, Palermo I-90127, Italy

Full list of author information is available at the end of the article
} 


\section{Background}

Osteoporosis and its resulting fractures are becoming major public health issues due to population ageing and the world-wide increase in long-term chronic conditions [1-3].

However, fractures in different populations considered at low risk of osteoporosis and with low-normal bone mineral density (BMD) have also been reported $[4,5]$.

Low BMD has emerged as a significant problem in chronically-infected patients, such as the HIV-infected population [1-3]. The mechanisms by which risk factors accelerate bone loss in human immunodeficiency virus (HIV)-infected subjects are unclear because of their complex and multifactorial nature [6]. The chronic inflammatory state induced by the virus itself may promote bone loss by increasing levels of pro-inflammatory cytokines such as tumor necrosis factor- $\alpha$ (TNF- $\alpha$ ), IL-6, IL-1 and NF-kappaB-ligand (RANKL), a member of the TNF superfamily of ligands and receptors $[1,6]$. Also weight loss, hypoparathyroidism and vitamin D deficiency resulting from HIV infection, as well as many antiretroviral drugs, may promote bone loss [7].

In addition to the traditional risk factors (i.e. older age, female sex, menopause, corticosteroid therapy, low BMI) attention has recently been centered on the importance of following a diet rich in calcium, other minerals and vitamin D associated with physical activity, which is recommended to maintain not only a healthy bone structure but also an acceptable BMD [8].

Since general risk factors and HIV-related factors affect both bone turnover and BMD, the aim of our study was to assess the prevalence of low BMD in HIVinfected subjects and controls and to analyze the effects of calcium intake and other environmental risk factors in order to increase current interest in the management of bone disease in the HIV-population through appropriate dietary and lifestyle interventions. We also estimated the 10-year fracture risk.

\section{Methods}

\section{Study population}

The study participants were Caucasian HIV-infected patients, consecutively enrolled between January 2011 and January 2012, who were being followed-up prospectively at the AIDS Center of the University of Palermo.

BMD was measured in all subjects by dual X-ray absorptiometry (DXA) [9]. Exclusion criteria included kidney disease, gastrointestinal disorders and steroid and sex steroid therapy.

Data on age, gender, drug addiction, antiretroviral therapy (ART), protease inhibitors (PI) and nonnucleoside reverse-transcriptase inhibitor (NNRTI) exposure were all recorded in a database designed for this study. Specific tenofovir exposure $>1$ year was also recorded. Exposures to ART and PI were graded 0 (no exposure) to 3 ( $1:$ < five years; 2 : from five to nine years; $3: \geq$ ten years).

Body mass index (BMI) was calculated as weight (in $\mathrm{kg}$ ) divided by height squared $\left(\mathrm{m}^{2}\right)$. Subjects were considered underweight when BMI was $\leq 18.5 \mathrm{~kg} / \mathrm{m}^{2}$, normal weight when BMI was between $18.6-24.9 \mathrm{~kg} / \mathrm{m}^{2}$, overweight when BMI was between $25-29.9 \mathrm{~kg} / \mathrm{m}^{2}$ and obese when BMI was $\geq 30 \mathrm{~kg} / \mathrm{m}^{2}$.

Diabetes mellitus was defined in accordance with the Expert Committee on the Diagnosis and Classification of Diabetes Mellitus criteria [10].

Seventy-six HIV-uninfected subjects referred by family doctors to our Center for laboratory and BMD assessment were enrolled as the control group. Age and sex of these subjects were comparable with the patients and the same exclusion criteria were applied.

\section{Interview data}

At the start of the study, the HIV-infected subjects filled in a health and lifestyle questionnaire considering medical and drug abuse history, lifestyle habits (including smoking status, alcohol consumption, Italian espresso coffee drinking, physical activity) and bone fractures. Smoking status was categorized as non-smokers, former smokers and current smokers. Alcohol intake $>20$ g per day either at the time of the study or in the past as well as Italian espresso coffee intake $>4$ cups per day were also recorded. Physical activity was defined as either non-occupational or occupational when physical exercise was performed during free time or at work, respectively. Non-occupational physical activity was considered active when $>2$ sessions of 20 minutes per week were performed. Occupational physical activity was defined as heavy when manual work was carried out.

In order to assess calcium intake, the consumption of foods representing the major sources of daily calcium intake in the Italian diet, such as typical Italian aged cheese (i.e. Parmesan), ricotta cheese and yogurt was recorded in a weekly food-frequency questionnaire, in accordance with the tables of nutrient values issued by the Italian National Institute of Nutrition [11-13]. This was administered through an individual face to-face interview [11]. A fixed range of food containers, i.e. a glass for milk and a cup for yogurt, was used to standardize portion sizes, each containing $\approx 300 \mathrm{mg}$ of calcium. A similar amount of calcium was contained in the reference servings of aged and ricotta cheese $(\approx 25$ and $100 \mathrm{~g}$, respectively). Color photographs were shown to the subjects to demonstrate the standard sizes of the cheese servings. In addition, the number of servings eaten weekly was recorded and calcium intake was categorized according to quartiles of weekly servings (1: $\leq 8,2: 9-10,3: 11-14$, and $4: \geq 15$ ), based on the distribution of the HIV-population. The level of education was 
also determined for all subjects. Three options were used: primary school (which in Italy represents a five-year compulsory education period), lower secondary school (three additional compulsory years) and higher levels of education, including upper secondary school, professional schools or university.

\section{Laboratory methods}

In all the HIV-patients CD4+ T-cell count (most recent value and nadir) and plasma HIV-RNA levels were assessed as previously reported [14]. Serum bone alkaline phosphatase, 25-hydroxyvitamin D, phosphorus and calcium levels were obtained in both HIV -infected cases and un-infected controls.

Vitamin D assessment was performed in the sunnier months from April through October, since it is known that vitamin $\mathrm{D}$ formation is not possible or inadequate [15] in Italy during the less sunny months, due to its latitude.

\section{Bone mineral density assessment}

For both HIV-infected cases and uninfected controls, BMD was assessed at baseline by DXA, using a QDR Discovery Hologic DXA in the femoral neck and DXA in the lumbar spine by total body DXA [16]. For each scan, BMD and T-scores were recorded. T-scores compare BMD with the mean of a healthy young (age 20-30 years) reference population, matched for sex and race, and were expressed as the number of standard deviations above or below the reference mean. Osteopenia was defined when at least one of the two DXA T-scores was less than -1 . Osteoporosis was diagnosed when either femoral neck or lumbar spine DXA T-scores were less than -2.5 , as recommended by the World Health Organization (WHO) and the National Osteoporosis Foundation [17-19].

We calculated the 10-year fracture risks according to the standardized WHO FRAX equation, computed with BMD (T-score) at the femoral neck [20].

\section{Statistical analysis}

Data were expressed as mean \pm standard deviation when distribution was Gaussian. Differences were calculated using Student's t-test. Otherwise, data were expressed as median and range and analyzed with the Mann-Whitney $U$ test. Fisher's exact and $\chi^{2}$ tests, Pearson's correlation and Spearman's rank correlation were used where appropriate. Multiple logistic regression analysis was performed to estimate the independence of the association between lumbar spine and femoral neck T-scores as well as variables significant at univariate analysis in the HIV-infected subjects. Variables contributing significantly to fit the logistic equation were then selected by a step-wise procedure. $P<0.05$ was considered significant.

All analyses were performed using the SPSS software package (version 16.0; Chicago, IL, USA).
The study protocol conformed to the ethical guidelines of the 1975 Declaration of Helsinki.

The study was approved by the local Ethics Committee and informed consent was obtained from all subjects.

\section{Results}

Characteristics of the HIV-infected population

The main characteristics of the 112 HIV-infected and control subjects are shown in Table 1 .

The average age of the recruited patients was $47 \pm 9.7$ years. Sixty-three individuals were male (56\%). Among the 112 subjects, 28 (25\%) were overweight, 6 (5\%) were underweight (BMI < 18.5) and $7(6 \%)$ were obese. As regards smoking status, drug addiction and Italian espresso coffee drinking we found that half of the study subjects regularly smoked cigarettes, one third drank coffee $>4$ times a day and one third used cocaine and/or heroin.

About half of this population did physical activity in their free time and had a higher level of education.

Concerning eating habits, the median daily calcium intake was $454 \mathrm{mg} / \mathrm{die}$, range (96-1359). More than half of the participants interviewed reported that they drank a glass of milk in the morning, whereas yogurt intake was less frequent. Parmesan cheese intake, according to our definition, was reported in about $90 \%$ of subjects.

Most subjects were on ART (93\%), seventy-five (67\%) had nadir CD4+ T-cell count $<200$ (cells/ $\mu \mathrm{L})$ and 41 (36.6\%) were co-infected with hepatitis $\mathrm{C}$ virus ( $\mathrm{HCV}$ ) (Table 1).

\section{Prevalence of osteopenia and osteoporosis in HIV- infected and uninfected subjects}

Osteopenia was present in 38 (34\%) HIV-infected vs 19 (25\%) HIV-uninfected subjects ( $p=n s)$. In detail, at the lumbar site osteopenia was present in 37 (33\%) HIVinfected vs 17 (22\%) HIV-uninfected subjects $(p<0.02)$; at the femoral site osteopenia was present in 42 (37.5\%) HIVinfected vs 18 (24\%) HIV-uninfected subjects ( $p=n s)$. In the setting of HIV-infection, osteopenia was present in 18 subjects at both the lumbar and femoral sites.

Osteoporosis was present in 34 (30.3\%) HIV-infected vs $8(10 \%) \mathrm{HIV}$-uninfected subjects $(p<0.05)$. At the lumbar site osteoporosis was present in 34 (30\%) HIVinfected vs $8(10 \%)$ HIV-uninfected subjects $(p<0.05)$; at the femoral site osteoporosis was present in $9(8 \%) \mathrm{HIV}-$ infected vs 4 (5\%) HIV-uninfected subjects ( $p=\mathrm{ns}$ ).

In the setting of HIV-infection osteoporosis was present in 9 subjects at both the lumbar and femoral sites.

\section{Comparison between lumbar spine and femoral neck DXA T-scores and biochemical parameters in HIV-infected and uninfected subjects}

Lumbar spine DXA T-score were significantly lower in HIV-infected (-1.4 range -5.2 to 1.6$)$ than in uninfected subjects $(-1$ range -4.4 to 2.7$)(p<0.02)$. No significant 
Table 1 Main characteristics of the 112 HIV-infected and 76 HIV-uninfected subjects

\begin{tabular}{|c|c|c|}
\hline & HIV+ & HIV- \\
\hline \multicolumn{3}{|l|}{ Demographic and lifestyle characteristics } \\
\hline Age years $\pm S D$ & $47 \pm 9.7$ & $49 \pm 11.3$ \\
\hline $\operatorname{Sex}(M / F)$ & $63 / 49$ & $42 / 34$ \\
\hline \multicolumn{3}{|l|}{ BMI $\left(\mathrm{kg} / \mathrm{m}^{2}\right)$ : } \\
\hline$<25$ & $77(68.7)$ & $47(62)$ \\
\hline$\geq 25-29$ & $28(25)$ & $23(30)$ \\
\hline$\geq 30$ & $7(6.2)$ & $6(8)$ \\
\hline Smoking status: & $37(33)$ & \\
\hline Non- smokers & & $44(58)$ \\
\hline Smokers & $58(53)$ & $21(28)$ \\
\hline Former smokers & $16(14)$ & $11(14)$ \\
\hline Free time physical activity & $57(51)$ & $45(60)$ \\
\hline Heavy workers & $16(14)$ & $10(13)$ \\
\hline Italian espresso caffeine intake ${ }^{1}$ & $30(27)$ & $23(29)$ \\
\hline Alcohol & $6(5)$ & $3(4)$ \\
\hline Diabetes & $20(18)$ & $11(14)$ \\
\hline \multicolumn{3}{|l|}{ Education: } \\
\hline Primary school & $34(30.3)$ & $20(26)$ \\
\hline Secondary school & $34(30.3)$ & $26(34)$ \\
\hline Higher level & $44(39.3)$ & $30(40)$ \\
\hline Postmenopause & $18(36.7)$ & $26(34)$ \\
\hline Fracture & $4(3.5)$ & $2(3)$ \\
\hline \multicolumn{3}{|l|}{ Calcium intake } \\
\hline Daily calcium intake (mg/day) (range) & $454(96-1359)$ & \\
\hline Dairy intake (times/week) (range) & $10(2-32)$ & \\
\hline Daily milk intake (ml/day) (range) & $200(0-800)$ & \\
\hline Yogurt intake & $36(32)$ & \\
\hline Yogurt intake (ml/week) & $0(0-1750)$ & \\
\hline Parmesan intake & $100(89)$ & \\
\hline \multicolumn{3}{|l|}{ Characteristics of HIV infection } \\
\hline Time since HIV diagnosis (years) (range) & $15(1-27)$ & \\
\hline Drug addiction & $28(25)$ & \\
\hline CD4+ T-cell count (cells/ $\mu \mathrm{L})$ (range) & $551(5-1082)$ & \\
\hline nadir CD4+ T-cell count <200 (cells/ $\mu \mathrm{L}$ ) & $75(67)$ & \\
\hline Undetectable HIV-RNA & $81(72.3)$ & \\
\hline ART & $104(93)$ & \\
\hline \multicolumn{3}{|l|}{ Duration of ART exposure: } \\
\hline$<5$ years & $18(17.3)$ & \\
\hline $5-9$ & $17(16.3)$ & \\
\hline$\geq 10$ & $69(66.3)$ & \\
\hline HCV infection & $41(36.6)$ & \\
\hline
\end{tabular}

${ }^{1}$ Italian espresso caffeine intake $=>4$ cups per day.

difference was found in femoral neck DXA T-score in patients with or without HIV-infection (data not shown).

Serum bone alkaline phosphatase was significantly higher in HIV-infected (54.7 range 19-170 IU/L) than uninfected subjects (28.2 range $5-84$ IU/L) $(p<0.0001)$, while phosphorus levels were lower in HIV-infected (3.1 range 1.4-4.4 $\mathrm{mg} / \mathrm{dL}$ ) than in uninfected subjects (3.5 range 2.1-6.8 $\mathrm{mg} / \mathrm{dL})(p<0.0001)$. 25-hydroxyvitamin $\mathrm{D}$ levels were also lower in $\mathrm{HIV}$-subjects (16.4 range 0.7$74 \mathrm{ng} / \mathrm{mL}$ ) than in controls (20 range $9-40.2 \mathrm{ng} / \mathrm{mL}$ ) $(p<0.02)$.

Calcium and parathyroid hormone levels were not significantly different in the two groups of patients (data not shown).

\section{Correlation between lumbar spine and femoral neck DXA} T-scores with demographic and environmental risk factors and calcium intake in HIV-infected subjects The correlations between the studied risk factors and lumbar spine and femoral neck DXA T-scores are presented in Table 2. Age was negatively correlated with BMD measured in both the lumbar spine and femoral neck $(p<0.05)$. Higher BMI values were positively correlated with BMD values measured in the femoral neck $(p<0.05)$.

No correlation was found between daily calcium intake (specifically milk), Parmesan, weekly consumption or quartile calcium intake and BMD measured in either the lumbar spine or femoral neck. Yogurt intake was positively correlated with BMD measured in the lumbar spine $(p<0.04)$.

By stratifying patients into two groups (milk or milk + yogurt) we found that osteopenia and osteoporosis were significantly higher in the patients with milk only than in those with milk + yogurt $\left(\chi_{M H}^{2}=5.6 ; p<0.02\right)$.

As regards biochemical markers, increasing values of bone alkaline phosphatase were negatively correlated with lumbar spine and femoral neck DXA T-scores $(p<0.002 ; p<0.005$, respectively).

\section{Correlation between lumbar spine and femoral neck DXA T-scores and characteristics of HIV- infection}

Duration of HIV-infection was negatively correlated with BMD in the femoral neck $(p<0.01)$. BMD in both lumbar spine and femoral neck DXA T-scores was negatively correlated with drug addiction $(p<0.04 ; p<0.02$, respectively), nadir CD $4+$ T-cell count $<200$ (cells $/ \mu \mathrm{L}$ ) $(p<0.05 ; p<0.04$, respectively), ART exposure score $(p<0.002 ; p<0.0001$, respectively), PI exposure score $(p<0.05 ; p<0.001$, respectively) and HCV co-infection $(p<0.001 ; p<0.005$, respectively) (Table 2$)$.

The mean of the 10-year risk of fracture, calculated in 76 HIV-infected subjects, was $1.2 \%$ for hip fracture and $4.7 \%$ for major osteoporotic fracture.

Figure 1 shows the positive correlation between BMI values and quartiles of dairy intake $(\rho=0.36 ; p<0.0001)$. Lower dairy intake quartiles were more frequent in subjects with osteoporosis than without, although the difference was not significant ( $\rho=-0.17 ; p=\mathrm{ns})$. 
Table 2 Correlation between lumbar spine, femoral neck DXA T-scores and the studied parameters in the HIV-infected patients

\begin{tabular}{|c|c|c|c|c|}
\hline & $\begin{array}{l}\text { Lumbar spine DXA T-score } \\
\qquad n=112\end{array}$ & $P<$ & $\begin{array}{l}\text { Femoral neck DXA T-score } \\
\qquad n=112\end{array}$ & $\mathbf{P}<$ \\
\hline \multicolumn{5}{|c|}{ DEMOGRAPHIC AND LIFESTYLE CHARACTERISTICS } \\
\hline Age $^{a}$ & -0.20 & 0.05 & -0.19 & 0.05 \\
\hline Female sex ${ }^{b}$ & 0.05 & ns & 0.07 & ns \\
\hline $\mathrm{BMI}\left(\mathrm{kg} / \mathrm{m}^{2}\right)^{\mathrm{a}}$ & 0.07 & ns & 0.11 & ns \\
\hline BMI score ${ }^{b, 1}$ & 0.14 & ns & 0.20 & 0.05 \\
\hline Smoking status ${ }^{b, 2}$ & -0.01 & ns & 0.09 & ns \\
\hline Free time physical activity ${ }^{b}$ & 0.14 & ns & 0.06 & ns \\
\hline Heavy workers ${ }^{b}$ & 0.02 & ns & 0.04 & ns \\
\hline Italian espresso caffeine intake b,3 & -0.04 & ns & -0.05 & ns \\
\hline Alcohol $^{b}$ & -0.03 & ns & 0.02 & ns \\
\hline Diabetes $^{b}$ & -0.14 & ns & -0.02 & ns \\
\hline Postmenopause $^{\mathrm{b}}$ & -0.17 & ns & -0.17 & ns \\
\hline Fracture $^{b}$ & -0.05 & ns & 0.17 & ns \\
\hline \multicolumn{5}{|l|}{ CALCIUM INTAKE } \\
\hline Daily calcium intake $(\mathrm{mg} / \text { day })^{\mathrm{a}}$ & 0.09 & ns & 0.05 & ns \\
\hline Dairy intake (times/week) ${ }^{a}$ & 0.09 & ns & 0.05 & ns \\
\hline Daily milk intake $(\mathrm{ml} / \text { day })^{a}$ & 0.07 & ns & 0.08 & ns \\
\hline Parmesan intake & 0.08 & ns & 0.15 & ns \\
\hline Yogurt intake $\left(\mathrm{ml} /\right.$ week) ${ }^{\mathbf{b}}$ & 0.23 & 0.04 & 0.11 & ns \\
\hline Dairy quartile intake (times /week) ${ }^{\mathrm{b}, 4}$ & 0.05 & ns & 0.04 & ns \\
\hline \multicolumn{5}{|l|}{ BIOCHEMICAL PARAMETERS } \\
\hline Calcium $(\mathrm{mg} / \mathrm{dL})^{\mathrm{a}}$ & 0.12 & ns & 0.08 & ns \\
\hline Phosphorus (mg/dL) ${ }^{a}$ & 0.09 & ns & 0.13 & ns \\
\hline Parathyroid hormone $(\mathrm{pg} / \mathrm{mL})^{\mathrm{a}}$ & -0.16 & ns & -0.13 & ns \\
\hline 25-Hydroxyvitamin $\mathrm{D}(\mathrm{ng} / \mathrm{mL})^{\mathrm{a}}$ & -0.05 & ns & -0.08 & ns \\
\hline Bone alkaline phosphatase (IU/L) ${ }^{a}$ & -0.34 & 0.002 & -0.32 & 0.005 \\
\hline \multicolumn{5}{|l|}{ CHARACTERISTICS OF HIV INFECTION } \\
\hline Drug addiction $^{\mathbf{b}}$ & -0.19 & 0.05 & -0.25 & 0.02 \\
\hline CD4+ T-cell count (cells/ $\mu \mathrm{L})^{\mathrm{a}}$ & 0.09 & ns & 0.12 & ns \\
\hline Nadir CD4+ <200 (cells/ $\mu \mathrm{L})^{b}$ & -0.22 & 0.05 & -0.23 & 0.04 \\
\hline Undetectable HIV-RNA ${ }^{\mathrm{b}}$ & 0.07 & ns & 0.09 & ns \\
\hline Time since HIV diagnosis $^{a}$ & -0.17 & ns & -0.25 & 0.01 \\
\hline Score of ART exposure ${ }^{b, 5}$ & -0.23 & 0.002 & -0.34 & 0.0001 \\
\hline Score of PI exposure ${ }^{b, 5}$ & -0.20 & 0.05 & -0.32 & 0.001 \\
\hline Duration tenofovir exposure $>1$ year $^{\mathrm{b}}$ & -0.12 & ns & -0.11 & ns \\
\hline NNRTI exposure ${ }^{\mathrm{b}}$ & -0.01 & ns & -0.01 & ns \\
\hline HCV infection ${ }^{b}$ & -0.30 & 0.001 & -0.27 & 0.005 \\
\hline Duration tenofovir exposure $>1$ year $^{b}$ & -0.12 & ns & -0.11 & ns \\
\hline NNRTI exposure & -0.01 & ns & -0.01 & ns \\
\hline HCV infection ${ }^{\mathrm{b}}$ & -0.30 & 0.001 & -0.27 & 0.005 \\
\hline
\end{tabular}

\section{DEMOGRAPHIC AND LIFESTYLE CHARACTERISTICS}

a: Pearson's correlation test; b: Spearman's rank correlation test.

${ }^{1}$ BMl score $=1:<25 ; 2: \geq 25-29 ; 3: \geq 30\left(\mathrm{~kg} / \mathrm{m}^{2}\right)$.

2 Smoking habits were graded 1: non- smokers, 2 smokers, 3 former smokers.

${ }^{3}$ Italian espresso caffeine intake $=>4$ cups per day.

${ }^{4}$ Dairy quartile intake (times $/$ week) $=1: \leq 8,2: 9-10,3: 11-14$, and $4: \geq 15$.

${ }^{5}$ ART and PI score =0: no exposure; $1:<5 ; 2: 5-9 ; 3: \geq 10$ years. 
No correlations between calcium intake and overall fracture risk at 10 years $(\mathrm{r}=-0.12 ; p=\mathrm{ns})$ and between calcium intake and risk of hip fracture at 10 years were found ( $\mathrm{r}=-0.13 ; p=\mathrm{ns})$.

At multiple linear regression analysis, age and HIV/ $\mathrm{HCV}$ co-infection were negatively correlated with BMD measured in the lumbar spine $(p<0.0001$; $p<0.005$, respectively), while an independent positive correlation was found between yogurt intake and $\mathrm{BMD}$ in the same site $(p<0.05)$. In the femoral neck T-score, age, nadir CD $4+\mathrm{T}$-cell count $<200$ (cells $/ \mu \mathrm{L}$ ) and drug addiction $(p<0.01 ; p<0.05 ; p<0.0001$, respectively) were negatively correlated with BMD (Table 3).

\section{Discussion}

To our knowledge, this is the first investigation on calcium intake and its relationship with BMD in adult subjects with HIV-infection. Previous studies in this area focused on calcium intake and its potential metabolic impact in HIV-subjects, or on its link with BMD in the subset of a HIV- pediatric population [21-23]. Despite the typical southern Italian regional habit of drinking a glass of milk with coffee in the morning (about $300 \mathrm{mg}$ of calcium), median daily calcium intake in our HIV- infected subjects was lower than the recommended daily amount, as reported by other Asian and European studies [24-26]. Milk is a good source of both calcium and vitamin $\mathrm{D}$ but other calcium-rich foods are needed to create a balanced diet assuring sufficient calcium and vitamin D intake in an HIV-population.

Parmesan cheese could be included in the "Mediterranean diet group" of foods because it is usually added to pasta and pizza. In fact, in our study interview Parmesan (25 g = $300 \mathrm{mg}$ calcium) was regularly consumed in $90 \%$ of the HIV-subjects.

Among the various dairy foods available we considered yogurt, which contains live active cultures and a substantial amount of calcium and vitamin D. Interestingly, we found that weekly yogurt intake was a protective independent predictor of BMD in the lumbar spine.

When the patients were divided into two groups the analysis showed a more favorable relationship between yogurt plus milk and BMD than milk alone. No previous study has examined the relationship between yogurt intake and BMD in HIV-infected subjects and only Sahni et al. [27] showed that milk and high yogurt intake were positively associated with hip and spine BMD in immunocompetent subjects in the Framingham Offspring Study.

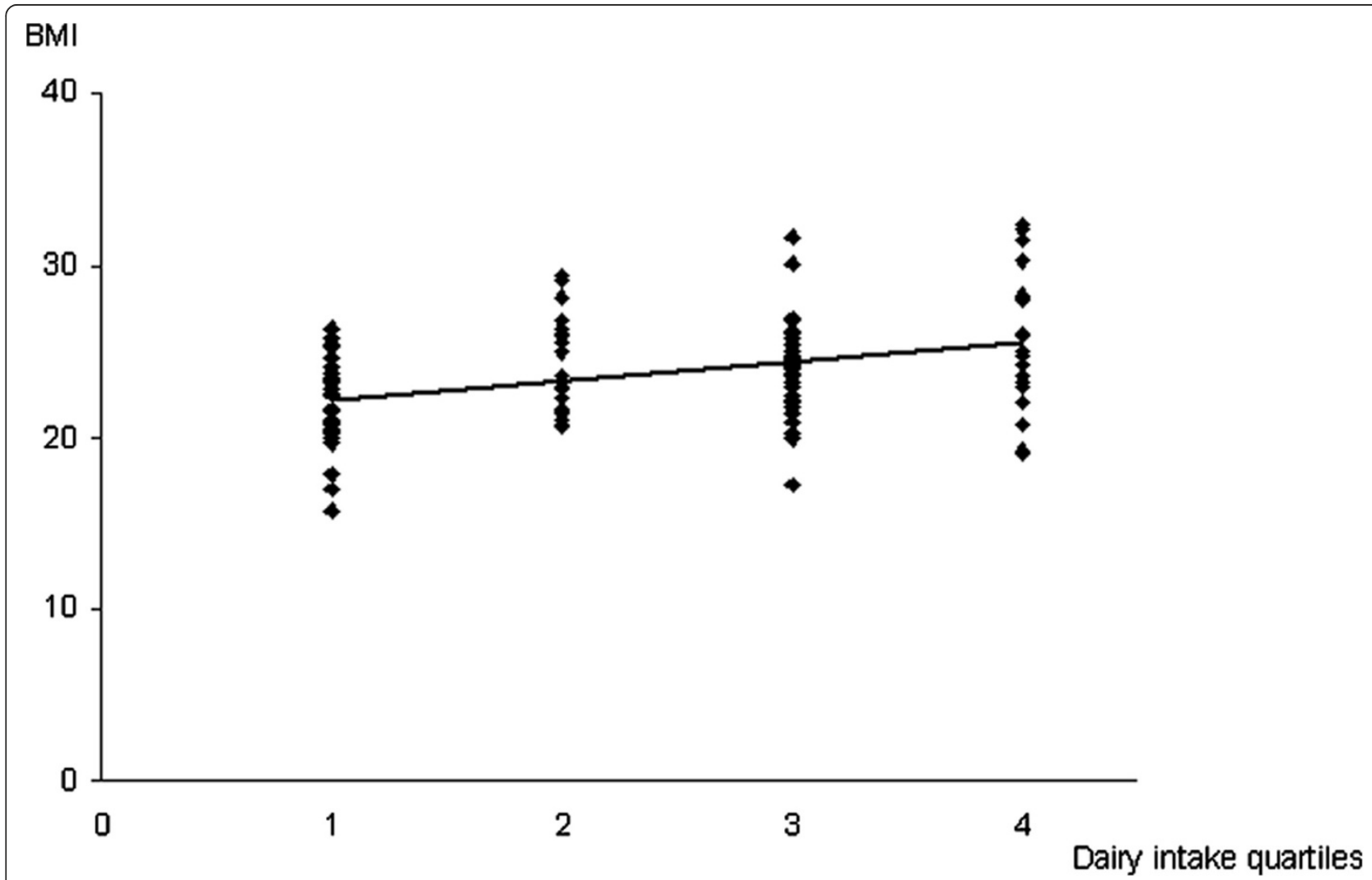

Figure 1 Correlation between BMI and dairy intake quartiles (times/week). The figure shows the significant Spearman's correlation between BMI values and dairy intake quartiles $(1: \leq 8,2: 9-10,3: 11-14$, and $4: \geq 15)$ in the HIV-infected subjects $(\rho=0.36 ; P<0.0001)$. 
Table 3 Multiple linear regression analysis of factors correlated with lumbar spine and femoral neck DXA T-scores

\begin{tabular}{|c|c|c|c|c|}
\hline \multirow[t]{2}{*}{ Variables } & \multicolumn{2}{|c|}{$\begin{array}{l}\text { Lumbar spine } \\
\text { DXA T-score }^{a}\end{array}$} & \multicolumn{2}{|l|}{$\begin{array}{l}\text { Femoral neck } \\
\text { DXA T-score }\end{array}$} \\
\hline & $\beta$-coefficient & $\mathbf{P}<$ & $\beta$-coefficient & $\mathrm{P}<$ \\
\hline HIV/HCV co-infection & -1.3 & 0.0001 & - & \\
\hline Age & -0.48 & 0.005 & -0.48 & 0.01 \\
\hline Yogurt intake & 0.3 & 0.05 & - & \\
\hline nadir CD4+ T-cell count $<200$ (cells/ $\mu \mathrm{L}$ ) & - & & -0.32 & 0.05 \\
\hline Drug addiction & - & & -1.4 & 0.0001 \\
\hline
\end{tabular}

${ }^{a}$ Variables excluded from the model for lumbar spine DXA T-score assessment: bone alkaline phosphatase, drug addiction , time since HIV diagnosis, score of ART and $\mathrm{PI}$ exposure.

${ }^{b}$ Variables excluded from the model for femoral neck DXA T-score assessment: BMI score, Bone alkaline phosphatase, time since HIV diagnosis, score of ART and $\mathrm{PI}$ exposure, HIV/HCV co-infection.

Probiotic microorganisms have considerable immunomodulatory effects in the gut-associated lymphoid tissue [28]. The importance of the gut microbiota for the development of the host's immune system and the suggested connection between gut microbiota and bone mass in mice led the researchers to investigate the impact of probiotic yogurt on bone mass, especially in the HIV- population [29]. Further studies are required to evaluate the gut microbiota and other micronutrients as a novel therapeutic target for osteoporosis [30].

In the present study the prevalence of osteoporosis was significantly higher in HIV- infected than in uninfected subjects, a result similar to previous meta-analyses [31].

Currently, more intensive investigations have been made to better understand whether HIV infection per se is a risk factor for low BMD $[1,7]$. Since the virus itself may induce hypovitaminosis $\mathrm{D}$ through many mechanisms (increased levels of TNF- $\alpha$, inhibition of renal hydroxylation and induction of 25-hydroxyvitamin D consumption by the macrophages and lymphocytes) $[7,32,33]$, the abnormal biochemical features found in our HIV-infected subjects compared with the controls, in particular the lower vitamin D levels, may support the hypothesis that HIV per se might play a role in the pathogenesis of bone loss. In addition, this finding in a sunny country like Italy might suggest the need to develop and recommend new key steps of calcium and vitamin $\mathrm{D}$ intake in the prevention of osteoporosis.

Several HIV-related factors were correlated with BMD on univariate analysis in both the lumbar spine and femoral neck in our HIV-infected subjects. The correlation between time of HIV diagnosis and BMD in the femoral neck as well as nadir CD4+ T-cell count $<200$ cells $/ \mu \mathrm{L}$ and BMD in both the lumbar spine and femoral neck and the finding that nadir $\mathrm{CD} 4+\mathrm{T}$-cell count $<200$ cells $/ \mu \mathrm{L}$ was an independent predictor of low BMD, suggest that HIV infection per se and in particular the more advanced stages of the disease might affect the skeletal system. This finding also suggests that an earlier commencement of ART might have a beneficial effect on BMD.
On the other hand, we found a significant negative correlation between longer duration of ART, especially PI exposure, and both lumbar spine and femoral neck BMD on univariate analysis.

How to strike a balance between the various aspects to be considered when providing ART, (such as when treatment should be commenced or the classes of drugs to be used, its influence on the progression of HIV disease and, in the present case, its effects on BMD) in order to maximize its benefits is an ongoing debate. In this respect, while Grund et al. [34] showed that BMD continuously declined in a HIV-group receiving continuous ART, Bolland et al. [35] found no evidence of accelerated bone loss over 6 years in middle-aged HIV-infected men treated with ART [36]. Many studies on the influence of ART have shown that the relative risk of low BMD is greater when PI are used [31,37-39], in agreement with our results. Unfortunately, we were unable to evaluate which drugs of the PI class were responsible for the low BMD, whereas other authors have shown that indinavir inhibits bone formation and lopinavir/ritonavir and atazanavir/ritonavir are associated with BMD loss $[31,39]$.

We did not find a significant correlation between tenofovir exposure $>1$ year and BMD in HIV-subjects, unlike previous reports [39,40]. Recent data showed that the introduction of tenofovir or emtricitabine/ tenofovir was associated with a $0.8 \%-1.1 \%$ decrease in BMD which occurred mainly within the first year in high-risk HIV-infected individuals [41]. In our study the small number of enrolled HIV subjects and the long exposure to different antiretroviral drugs made it difficult to show the real impact of tenofovir exposure on BMD health.

Moreover, no significant correlation was found between the small number of fractures reported in our HIV- subjects and BMD at either of the sites. In a recent Italian study, metabolic factors such as BMI and diabetes mellitus were independently correlated with vertebral fractures in HIV-infected patients [42]. Although low BMD in the setting of HIV-infection is frequently 
observed, data on its relationship with fracture rate are still under investigation [43].

To improve the ability to predict subsequent fragility fracture in our patients, we used the WHO FRAX equation [20]. Although fracture risk at ten years and calcium intake showed an inverse relationship this was not statistically significant. However, the role of the FRAX score in the HIV-population is still under debate because the HIV-independent risk factors, HIV-related parameters and ART characteristics were not evaluated by the score itself [44].

Similar to other studies on enrolled HIV-infected subjects with a long duration of infection, we found that older age and BMI values had a negative or positive correlation with BMD, respectively [45-47]. In this respect, a meta-analysis on ten studies showed that low BMI was the main factor behind the lower BMD values in HIVinfected than in normal uninfected individuals [47].

The results regarding the relationship between dairy product consumption and BMI are contradictory [48]. However, some cross-sectional data suggest that lowerfat dairy products such as milk and yogurt are associated with lower adiposity [48]. The positive correlation between higher BMI values and BMD in the femoral neck DXA T-score or the increasing quartiles of calcium intake, suggest a protective role for calcium intake in the prevention of BMD loss in our HIV-subjects [49]. This observation may also encourage physicians to recommend an increase in calcium consumption especially in HIV-subjects with low BMD.

However, the ideal daily calcium intake to prevent osteoporosis in HIV-positive subjects is not clear because it depends not only on known general and environmental risk factors but also on the patient's long-term immuno-virological course.

For most people, a daily calcium intake of between 1000 and $1300 \mathrm{mg}$ is both safe and potent but we hypothesize that the dose should be reviewed in relation to ART and HIV-status.

Recent data have suggested that patients with AIDS and addicted to heroin might be at particular risk for bone loss [50]. The independent negative correlation found between drug addiction and low BMD in our HIV subjects confirms this finding.

Another interesting result emerging from our study is the independent correlation between $\mathrm{HIV} / \mathrm{HCV}$ coinfection and BMD.

Vitamin D deficiency was found in HIV/HCV coinfected patients [51]. Moreover, higher vitamin D levels were independently associated with a rapid virological response in patients with genotype 1 chronic hepatitis $\mathrm{C}$ [52]. Increasing vitamin D intake may positively modulate the response to antiviral treatment in $\mathrm{HCV}$-infected or $\mathrm{HIV} / \mathrm{HCV}$ co-infected patients. Further research is necessary to better understand the impact of viral hepatitis on BMD in HIV-infected and uninfected subjects and discuss the clinical applications and future direction of this field [53].

\section{Conclusions}

To our knowledge, this is the only study to date to evaluate calcium intake and low BMD in HIV-infected subjects. Two interesting findings emerge from our study, firstly, among the foods rich in calcium yogurt was an independent protective predictor of BMD in HIV-subjects; second, HIV/HCV co-infection, drug addiction and nadir CD4+ T-cell count $<200$ cells $/ \mu \mathrm{L}$ were independent predictors of severe bone disease. It seems essential to implement medical treatment by promoting behavioral changes in food intake and lifestyle in the primary prevention of bone disease in chronically-infected people.

\section{Abbreviations}

HIV: human immunodeficiency virus; BMD: bone mineral density; TNFa: tumor necrosis factor-a; ART: antiretroviral therapy; PI: protease inhibitors; NNRTI: non-nucleoside reverse-transcriptase inhibitors; BMl: body mass index; DXA: dual-energy radiographic absorptiometry; AIDS: acquired immunodeficiency syndrome; Vs: versus.

\section{Competing interests}

The authors declare that they have no competing interests with respect to this article.

\section{Authors' contributions}

VLV and PDC designed the study and drafted the manuscript. MS participated in the design of the study and performed the statistical analysis. LG, GM, SLS, CC and SM set up and conducted the study in the field and contributed to the interpretation of the results. GC carried out the DXA. FT carried out the laboratory analysis. The ethics applications and funding applications were submitted by PM and PDC as principal investigators in the control group. GM and PDC conceived the study, and participated in its design and coordination. All authors read and approved the final manuscript.

\section{Author details}

'Dipartimento di Medicina Interna, Università di Palermo, Via del Vespro 141, Palermo 1-90127, Italy. ${ }^{2}$ Dipartimento di Medicina Clinica e delle Patologie Emergenti, Azienda Ospedaliera Universitaria Policlinico "Paolo Giaccone" di Palermo, Via del Vespro 133, Palermo I-90127, Italy. ${ }^{3}$ Dipartimento di Scienze per la Promozione della Salute, Università di Palermo, Via del Vespro 133, Palermol-90127, Italy. ${ }^{4}$ Dipartimento di Biotecnologie Mediche e Medicina Legale, Università di Palermo, Via del Vespro 133, Palermo I-90127, Italy.

Received: 13 April 2012 Accepted: 23 July 2012

Published: 15 August 2012

\section{References}

1. Mansky KC: Aging, human immunodeficiency virus, and bone health. Clin Interv Aging 2010, 5:285-292.

2. Luxon BA: Bone disorders in chronic liver diseases. Curr Gastroenterol Rep 2011, 13:40-48.

3. Goel V, Kar P: Hepatic osteodystrophy. Trop Gastroenterol 2010, 31:82-86.

4. Mazziotti G, Bianchi A, Bonadonna S, Cimino V, Patelli I, Fusco A, Pontecorvi $A$, De Marinis L, Giustina A: Prevalence of vertebral fractures in men with acromegaly. J Clin Endocrinol Metab 2008, 93:4649-4655.

5. Mancini T, Mazziotti G, Doga M, Carpinteri R, Simetovic N, Vescovi PP, Giustina A: Vertebral fractures in males with type 2 diabetes treated with rosiglitazone. Bone 2009, 45:784-788.

6. Martin TJ: Paracrine regulation of osteoclast formation and activity: milestones in discovery. J Musculoskelet Neuronal Interact 2004, 4:243-253. 
7. Lima AL, de Oliveira PR, Plapler PG, Marcolino FM, de Souza Meirelles E, Sugawara A, Gobbi RG, Dos Santos AL, Camanho GL: Osteopenia and osteoporosis in people living with HIV: multiprofessional approach. HIV AIDS (Auckl) 2011, 3:117-124.

8. Musumeci M, Vadalà G, Tringali G, Insirello E, Roccazzello AM, Simpore J, Musumeci S: Genetic and environmental factors in human osteoporosis from Sub-Saharan to Mediterranean areas. J Bone Miner Metab 2009, 27:424-434.

9. Carmina E, Di Fede G, Napoli N, Renda G, Vitale G, Lo Pinto C, Bruno D Malizia R, Rini GB: Hypogonadism and hormone replacement therapy on bone mass of adult women with thalassemia major. Calcif Tissue Int 2004 74:68-71.

10. Alberti KG, Zimmet P, Shaw J, IDF epidemiology task force consensus group: The metabolic syndrome-a new worldwide definition. Lancet 2005, 366:1059-1061.

11. Varenna M, Binelli L, Casari S, Zucchi F, Sinigaglia L: Effects of dietary calcium intake on body weight and prevalence of osteoporosis in early postmenopausal women. Am J Clin Nutr 2007, 86:639-644.

12. Carnovale E, Marletta L: Food composition tables. Rome: Italian National Institute of Nutrition; 1997.

13. Krogh V, Freudenheim $J$ L, D'Amicis A: Food sources of nutrients of the diet of elderly Italians: II Micronutrients. Int J Epidemio/ 1993, 22:869-877.

14. Bonura F, Tramuto F, Vitale F, Perna AM, Viviano E, Romano N, Group for HIV-1 Antiretroviral Studies in Sicily: Transmission of drug-resistant HIV type 1 strains in HAART-naive patients: a 5-year retrospective study in Sicily, Italy. AIDS Res Hum Retroviruses 2010, 26:961-965.

15. Focà E, Motta D, Borderi M, Gotti D, Albini L, Calabresi A, Izzo I, Bellagamba R, Narciso P, Sighinolfi L, Clò A, Gibellini D, Quiros-Roldan E, Brianese N, Cesana BM, Re MC, Torti C: Prospective evaluation of bone markers, parathormone and $1,25-(\mathrm{OH})_{2}$ vitamin D in HIV-positive patients after the initiation of tenofovir/emtricitabine with atazanavir/ritonavir or efavirenz. BMC Infect Dis 2012, 12:38.

16. Carmina E, Bucchieri S, Esposito A, Del Puente A, Mansueto P, Di Fede G, Rini GB: Abdominal fat quantity and distribution in women with polycystic ovary syndrome and extent of its relation to insulin resistance. J Clin Endocrinol Metab 2007, 92:2500-2505.

17. Report of a WHO Study Group: Assessment of fracture risk and its application to screening for postmenopausal osteoporosis. World Health Organ Tech Rep Ser 1994, 843:1-129.

18. National Osteoporosis Foundation: Clinician's Guide to Prevention and Treatment of Osteoporosis. Washington, DC: National Osteoporosis Foundation; 2010.

19. Berry SD, Kiel DP, Donaldson MG, Cummings SR, Kanis JA, Johansson H, Samelson EJ: Application of the National Osteoporosis Foundation Guidelines to postmenopausal women and men: the Framingham Osteoporosis Study. Osteoporos Int 2010, 21:53-60

20. FRAX: WHO fracture risk assessment tool. http://www.shef.ac.uk/FRAX/

21. Smit E, Graham NM, Tang A, Flynn C, Solomon L, Vlahov D: Dietary intake of community-based HIV-1 seropositive and seronegative injecting drug users. Nutrition 1996, 12:496-501.

22. Leite LH, Sampaio AB: Dietary calcium, dairy food intake and metabolic abnormalities in HIV-infected individuals. J Hum Nutr Diet 2010, 23:535-543.

23. Jacobson DL, Spiegelman D, Duggan C, Weinberg GA, Bechard L, Furuta L, Nicchitta J, Gorbach SL, Miller TL: Predictors of bone mineral density in human immunodeficiency virus-1 infected children. J Pediatr Gastroenterol Nutr 2005, 41:339-346.

24. Lau EM, Suriwongpaisal P, Lee JK, De Das S, Festin MR, Saw SM, Khir A, Torralba T, Sham A, Sambrook P: Risk factors for hip fracture in Asian men and women: the Asian osteoporosis study. J Bone Miner Res 2001, 16:572-580.

25. Jha RM, Mithal A, Malhotra N, Brown EM: Pilot case-control investigation of risk factors for hip fractures in the urban Indian population. BMC Musculoskelet Disord 2010, 11:49.

26. Johnell O, Gullberg B, Kanis JA, Allander E, Elffors L, Dequeker J, Dilsen G, Gennari C, Lopes Vaz A, Lyritis G: Risk factors for hip fracture in European women: the MEDOS Study. Mediterranean Osteoporosis Study. J Bone Miner Res 1995, 10:1802-1815.

27. Sahni S, Tucker KL, Kiel DP, Quach L, Casey V, Hannan MT: Positive Association of Total Dairy and Milk Intake with Bone Mineral Density (BMD):
Results from the Framingham Offspring Study. San Diego: The American Society for Bone and Mineral Research, Annual Meeting; 2011. 19 September.

28. Sjögren $K$, Engdahl C, Henning P, Lerner UH, Tremaroli V, Lagerquist MK, Bäckhed F, Ohlsson C: The gut microbiota regulates bone mass in mice. J Bone Miner Res 2012, 27:1357-1367.

29. Cunningham-Rundles $S$, Ahrné $S$, Johann-Liang R, Abuav R, Dunn-Navarra AM, Grassey C, Bengmark S, Cervia JS: Effect of probiotic bacteria on microbial host defense, growth, and immune function in human immunodeficiency virus type-1 infection. Nutrients 2011, 3:1042-1070.

30. Nunnari G, Coco C, Pinzone MR, Pavone P, Berretta M, Di Rosa M, Schnell M, Calabrese G, Cacopardo B: The role of micronutrients in the diet of HIV-1infected individuals. Front Biosci (Elite Ed) 2012, 4:2442-2456.

31. Brown TT, Qaqish RB: Antiretroviral therapy and the prevalence of osteopenia and osteoporosis: a meta-analytic review. AIDS 2006, 20:2165-2174

32. Haug CJ, Aukrust P, Haug E, Mørkrid L, Müller F, Frøland SS: Severe deficiency of 1,25-dihydroxyvitamin D3 in human immunodeficiency virus infection: association with immunological hyperactivity and only minor changes in calcium homeostasis. J Clin Endocrinol Metab 1998, 83:3832-3838

33. Conrado T, Miranda-Filho Dde B, Bandeira F: Vitamin D deficiency in HIVinfected individuals: one more risk factor for bone loss and cardiovascular disease? Ara Bras Endocrinol Metabol 2010, 54:118-122.

34. Grund B, Peng G, Gibert CL, Hoy JF, Isaksson RL, Shlay JC, Martinez E, Reiss P, Visnegarwala F, Carr AD, INSIGHT SMART Body Composition Substudy Group: Continuous antiretroviral therapy decreases bone mineral density. AIDS 2009, 23:1519-1529.

35. Bolland MJ, Grey A, Horne AM, Briggs SE, Thomas MG, Ellis-Pegler RB, Gamble GD, Reid IR: Stable bone mineral density over six years in HIVinfected men treated with highly active anti-retroviral therapy (HAART). Clin Endocrinol (Oxf), in press.

36. Jain RG, Lenhard JM: Select HIV protease inhibitors alter bone and fat metabolism ex vivo. J Biol Chem 2002, 277:19247-19250

37. Tan BM, Nelson RP Jr, James-Yarish M, Emmnueal P, Schurman SJ: Bone metabolism in children with human immunodeficiency virus infection receiving highly active anti-retroviral therapy including a protease inhibitor. J Pediatr 2001, 139:447-451.

38. Fernández-Rivera J, García R, Lozano F, Macías J, García-García JA, Mira JA, Corzo JE, Gómez-Mateos J, Rueda A, Sánchez-Burson J, Pineda JA: Relationship between low bone mineral density and highly active antiretroviral therapy including protease inhibitors in HIV-infected patients. HIV Clin Trials 2003, 4:337-346.

39. McComsey GA, Tebas P, Shane E, Yin MT, Overton ET, Huang JS, Aldrovand GM, Cardoso SW, Santana JL, Brown TT: Bone disease in HIV infection: a practical review and recommendations for HIV care providers. Clin Infect Dis 2010, 51:937-946.

40. Yin MT, Overton ET: Increasing clarity on bone loss associated with antiretroviral initiation. J Infect Dis 2011, 203:1705-1707.

41. Liu AY, Vittinghoff $E$, Sellmeyer DE, Irvin R, Mulligan $K$, Mayer $K$, Thompson M, Grant R, Pathak S, O'Hara B, Gvetadze R, Chillag K, Grohskopf L, Buchbinder SP: Bone mineral density in HIV-negative men participating in a tenofovir pre-exposure prophylaxis randomized clinical trial in San Francisco. PLoS One 2011, 6:e23688.

42. Torti C, Mazziotti G, Soldini PA, Focà E, Maroldi R, Gotti D, Carosi G, Giustina A: High prevalence of radiological vertebral fractures in HIV-infected males. Endocr 2012, 41:512-517.

43. Gazzaruso C: An increased risk for fractures: another cause of frailty in HIV-infected subjects. Endocrine 2012, 41:347-349.

44. Calmy A, Fux CA, Norris R, Vallier N, Delhumeau C, Samaras K, Hesse K, Hirschel B, Cooper DA, Carr A: Low bone mineral density, renal dysfunction, and fracture risk in HIV infection: a cross-sectional study. J Infect Dis 2009, 200:1746-1754.

45. Mondy K, Yarasheski K, Powderly WG, Whyte M, Claxton S, DeMarco D, Hoffmann $M$, Tebas $P$ : Longitudinal evolution of bone mineral density and bone markers in human immunodeficiency virus-infected individuals. Clin Infect Dis 2003, 36:482-490.

46. Thomas J, Doherty SM: HIV infection-a risk factor for osteoporosis. J Acquir Immune Defic Syndr 2003, 33:281-291.

47. Bolland MJ, Grey AB, Gamble GD, Reid IR: CLINICAL Review \#: low body weight mediates the relationship between HIV infection and low bone 
mineral density: a meta-analysis. J Clin Endocrinol Metab 2007,

92:4522-4528.

48. Dougkas A, Reynolds CK, Givens ID, Elwood PC, Minihane AM: Associations between dairy consumption and body weight: a review of the evidence and underlying mechanisms. Nutr Res Rev 2011, 24:72-95.

49. Warensjö E, Byberg L, Melhus H, Gedeborg R, Mallmin H, Wolk A, Michaëlsson K: Dietary calcium intake and risk of fracture and osteoporosis: prospective longitudinal cohort study. BMJ 2011, 342:d1473.

50. Sharma A, Flom PL, Weedon J, Klein RS: Prospective study of bone mineral density changes in aging men with or at risk for HIV infection. AIDS 2010, 24:2337-2345.

51. Etminani-Esfahani M, Khalili H, Soleimani $N$, Jafari S, Abdollahi A, Khazaeipour Z, Gholami K: Serum vitamin D concentration and potential risk factors for its deficiency in HIV positive individuals. Curr HIV Res 2012, 10:165-170.

52. Petta S, Ferraro D, Cammà C, Cabibi D, Di Cristina A, Di Marco V, Di Stefano R, Grimaudo S, Mazzola A, Levrero M, Scazzone C, Craxì A: Vitamin D levels and IL28B polymorphisms are related to rapid virological response to standard of care in genotype 1 chronic hepatitis C. Antivir Ther 2012, in press.

53. Lo Re V 3rd, Guaraldi G, Leonard MB, Localio AR, Lin J, Orlando G, Zirilli L, Rochira V, Kostman JR, Tebas P: Viral hepatitis is associated with reduced bone mineral density in HIV-infected women but not men. AIDS 2009, 23:2191-2198.

doi:10.1186/1471-2334-12-192

Cite this article as: Li Vecchi et al.: Dairy calcium intake and lifestyle risk factors for bone loss in hiv-infected and uninfected mediterranean subjects. BMC Infectious Diseases 2012 12:192.

\section{Submit your next manuscript to BioMed Central and take full advantage of:}

- Convenient online submission

- Thorough peer review

- No space constraints or color figure charges

- Immediate publication on acceptance

- Inclusion in PubMed, CAS, Scopus and Google Scholar

- Research which is freely available for redistribution 